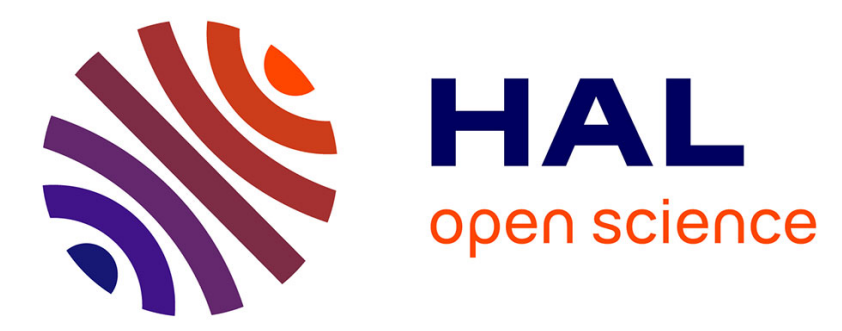

\title{
Power Consumption Reduction of a Controlled Friction Tactile Plate
}

\author{
Frédéric Giraud, Michel Amberg, Romuald Vanbelleghem, Betty
}

Lemaire-Semail

\section{- To cite this version:}

Frédéric Giraud, Michel Amberg, Romuald Vanbelleghem, Betty Lemaire-Semail. Power Consumption Reduction of a Controlled Friction Tactile Plate. Lecture Notes in Computer Science, 6192, pp.44 49, 2010, 10.1007/978-3-642-14075-4_7 . hal-01110765

\section{HAL Id: hal-01110765 \\ https://hal.science/hal-01110765}

Submitted on 28 Jan 2015

HAL is a multi-disciplinary open access archive for the deposit and dissemination of scientific research documents, whether they are published or not. The documents may come from teaching and research institutions in France or abroad, or from public or private research centers.
L'archive ouverte pluridisciplinaire HAL, est destinée au dépôt et à la diffusion de documents scientifiques de niveau recherche, publiés ou non, émanant des établissements d'enseignement et de recherche français ou étrangers, des laboratoires publics ou privés. 


\title{
Power consumption reduction of a controlled friction Tactile Plate
}

\author{
Frédéric Giraud ${ }^{1}$, Michel Amberg ${ }^{1}$, Romuald Vanbelleghem ${ }^{2}$, and Betty \\ Lemaire-Semail $^{1}$ \\ ${ }^{1}$ Univ Lille Nord de France, F59000 Lille, France \\ frederic.giraud@polytech-lille.fr \\ 2 INRIA Lille Nord Europe, F59000 Lille, France
}

\begin{abstract}
This paper describes design improvements of a friction reduction based tactile device, which yields to reduction of the supply power. We first evaluated the power consumption of four different plates. We found that a convenient design could cut the power losses down by $90 \%$. To explain these changes we propose a modelling of the dielectric losses in the piezoelectric actuators and of the vibration amplitude.
\end{abstract}

Key words: haptic interface, tactile interface, surface friction, power reduction.

\section{Introduction}

One way to enhance interaction between man and the machine is to provide tactile stimulation to the user. By this way, information can be provided through the sense of touch. To achieve that, many tactile displays have been designed and can be divided into three groups, according to their working principle. Devices made up with a large number of pins arranged in an array [1][2] reconstruct the geometry of a virtual surface. Other tactile stimulators don't create the exact geometry of a virtual surface, but the effect of this geometry on the finger pulp. For example, [3] uses an array of small pins that vibrate to excite each R.A. mechanoreceptor independently. In [4][5], the skin is stretched to give the sensation of touching a real bump or a hole. Those two types of tactile stimulator create a local stimulation. But tactile stimulators using a global stimulation can be found as well. Devices based on friction reduction belong to this category. They use a vibrating plate at very high frequency (typically above $25 k \mathrm{~Hz}$ ) on which the finger is free to move. The vibration creates an airgap which decreases friction between fingertip and the plate. By turning on and off the power supply of the device, the stimuli generated by this temporal friction variation create the illusion of a more or less finely textured surface. Previous designs of such a tactile plate have been made[6]. This plate, called the original plate suffered from the heat generated by the plate, which could hurt users. To solve this problem, we study the design of the tactile plate in the light of power consumption.

The paper is organized as follows. First we describe the original tactile plate and the squeeze film effect. Then we analyze the power consumption of three new 
designs of the tactile plate. A modelling of the power losses is then proposed, which explains the differences in power consumption between the new designs. Finally a discussion highlights the influence of the plate's dimension on power consumption.

\section{Presentation of the original tactile plate}

The friction reduction occurring between fingertip and a vibrating plate is often explained using «squeeze film air bearing》 theory which is detailed in [7] and applied on a tactile device in [8-10]. On a practical approach, an overpressure between the fingertip and the plate is created by the vibrations, resulting in a friction reduction. The plates described in this article use a standing flexural wave which propagates at the plate's surface. This design allows high vibration amplitude with small bulk size. To create the vibration, 28 piezo cells are bonded onto a copper substrate; when supplied by a sinusoidal voltage, they bend the substrate as shown in figure 1.
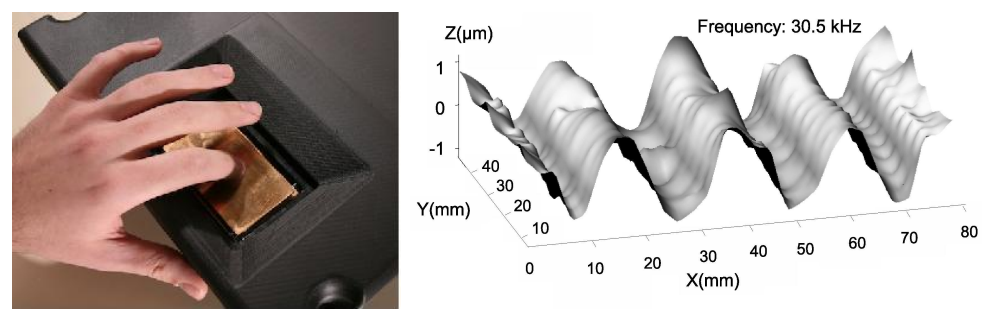

Fig. 1. An ultrasonic tactile plate and the measured deformed shape.

One important thing to explain, is that when moving the fingertip on the plate, users don't feel the vibration by itself, but the effect of the vibration on the tribological behaviour of the contact between the finger and the plate. Moreover, the vibration is not homogenous, due to the vibration nodes and antinodes; however, the squeeze film effect is more or less filtered because touching area is in the same order of size as the vibration wavelength.

To be efficient, the plate should be designed so as to allow vibrations at $25 \mathrm{kHz}$ and above, otherwise the squeeze effect is not created. Moreover, a typical vibration amplitude of $1 \mu \mathrm{m}$ is necessary in order to attain a sufficiently low friction level. The original plate has been designed to offer those performances[6]. Its size was chosen in order to optimize the vibration amplitude for a given voltage amplitude $V$. However, in this design, plate thickness has been fixed to $2 \mathrm{~mm}$ and the piezo cells'thickness to $1 \mathrm{~mm}$. Moreover, the optimization process paid no attention to the power requirements of the tactile plate, which actually needs a large amount of power to be supplied. Consequently, the device's temperature increases because of the power losses, leading to burning sensations. Reducing 
the losses is a key issue in these devices to allow a use over a long duration. The following section of this article presents several new designs which help to reduce the required power supplied to the device.

\section{Loss reduction}

\subsection{Experimental approach}

The tactile plate is built up with piezoceramics bonded on a copper-beryllium substrate. In order to find which design produces less power losses at a given vibration amplitude, we built up several tactile plates with different sizes:

- plate 0: the original plate, the wavelength of which is $\lambda=20.6 \mathrm{~mm}$,

- plate 1: same as the plate $\mathbf{0}$ but the substrate's thickness is set to $0.7 \mathrm{~mm}$,

- plate 2: same as plate $\mathbf{1}$, but the ceramics' thickness is changed to $0.5 \mathrm{~mm}$,

- plate 3: a new plate with $\lambda=15.6 \mathrm{~mm}$, a substrate's thickness of $0.75 \mathrm{~mm}$ and piezo ceramics' thickness of $0.5 \mathrm{~mm}$.

We then measured the required power as a function of $W$. Results are presented in figure 2. As it can be seen, the supply power required for the original tactile plate dramatically increases with the vibration amplitude. Moreover, it appears that plates with thicker piezoelectric cells exhibit larger vibration amplitude for the same amount of power consumption.

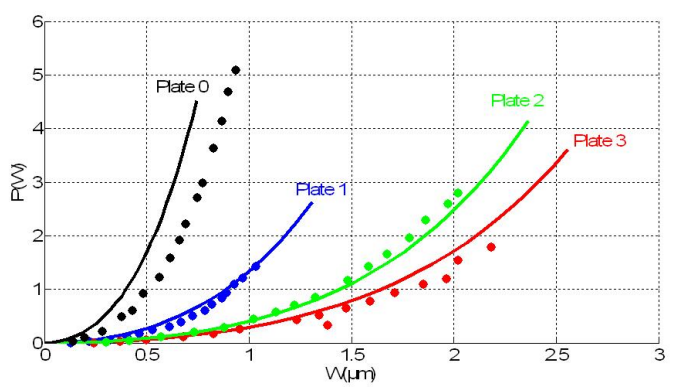

Fig. 2. Required power as a function of the vibration amplitude, for several plate designs. line: modelling, dots: experimental measurements.

We also measured the vibration of the plate as a function of the supply voltage. The results are presented in figure 3. It appears that for plate $\mathbf{0}$ and plate $\mathbf{1}$, the deflexion saturates to almost $1 \mu \mathrm{m}$. When trying to vibrate more than $1 \mu m$, and thus providing more voltage to the plates, we supply with much more power but we don't obtain more deflection: the additional amount of power is lost into heat, without increasing the vibration amplitude. The other two designs plates $\mathbf{2}$ and $\mathbf{3}$, also saturate but at a higher level. These designs are more convenient to the use in a tactile stimulator. 


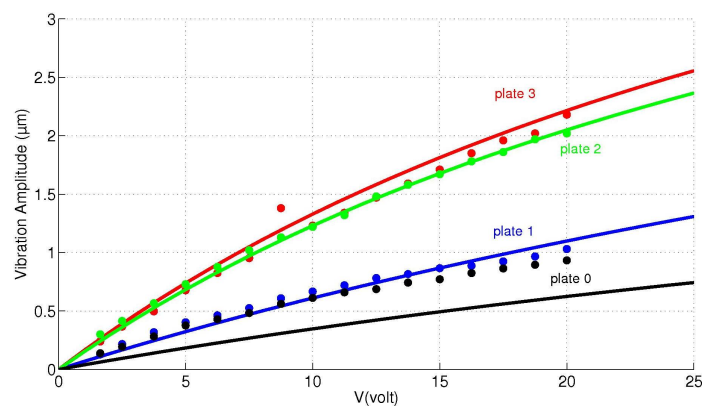

Fig. 3. Vibration amplitude as a function of the voltage supplied to the device, for several plate designs. line: modelling, dots: experimental measurements.

Comparing plate $\mathbf{0}$ and plate $\mathbf{1}$, we find that we can reduce power consumption using a thin substrate. In fact, both plates output the same deformation amplitude, but the thinnest plate consumes less. However, those plates saturate at a low level of deflection, and $1 \mu \mathrm{m}$ is a maximum value one may expect with them. A better design seems to be plates $\mathbf{2}$ and $\mathbf{3}$. For those plates, we used thin piezo cells: those plates don't saturate at $1 \mu \mathrm{m}$, and the required power is very low compared to the other designs. As a conclusion to this experimental study, we can describe the effect of the plate's parameters as follows:

- reducing substrate's thickness reduces power consumption and has no effect on the maximum vibration amplitude,

- reducing piezoelectric actuator's thickness reduces power consumption and also increases the maximum vibration amplitude.

The next section of this paper explains which role plays the thickness of the piezo layer, and also gives a modelling of the power losses and the vibration amplitude. This step is important to design an optimized plate.

\subsection{Discussion}

The reason why original plate requires so much power compared to the others is that the design was optimized to produce large vibration amplitude at a given voltage. This design was not optimized to reduce power losses. One mechanism leading to power losses is the presence of dielectric losses inside the piezoelectric cells. The piezo product manufacturer [11] gives the relationship between the voltage supplied to the piezo element $V$, its capacitance $C_{0}$, the working frequency $f$ and the power losses $P$ by introducing the parameter $\delta$ :

$$
P=(2 \pi f) C_{0} V^{2} \tan (\delta)
$$

The capacitance $C_{0}$ is given by the cell's dimension:

$$
C_{0}=\varepsilon \frac{a \times b}{e}
$$


Where $a \times b$ is cells' surface, $\varepsilon$ is the material's dielectric constant and $e$ is the piezo-thickness. Introducing 2 into 1 leads to:

$$
P=(2 \pi f) \frac{V^{2}}{e} \varepsilon(a \times b) \tan (\delta)
$$

As it can be seen, the power losses depend on the resonance frequency of the plate. This is verified by experimental data, because the frequency of the three new plates is lower than the original one. In this study, the plates didn't fully fulfill requirements of section 2 because the resonance frequency was around $20 \mathrm{kHz}$ instead of the required $25 \mathrm{kHz}$. However, conclusion to the work doesn't change.

Moreover, the power losses are proportional to the ratio $\frac{V^{2}}{e}$ : for a given substrate and piezoelectric material, cells thickness should be as big as possible to reduce power losses. However, this fact is not consistent with conclusion of section 3.1. In fact, in this application, the device doesn't work at constant voltage, but at constant vibration amplitude. This is why, this modelling must be completed with the relationship between the vibration amplitude and the voltage.

This vibration modelling is extracted from [6] to deduce the vibration amplitude as a function of $V$, allowing the drawing of the curves in figure 3 . In this paper, we do not fully describe this modelling, but we focus on the fact that the vibration amplitude is proportional to $Q_{m} d_{31} \frac{V}{e^{2}}$ where $d_{31}$ is an elongation factor of the piezoelectric material, and $Q_{m}$ is a quality factor of the mechanical resonator.

Normally, $Q_{m}$ and $d_{31}$ are constant; however, to take into account non linearity of the piezo material, and reach to the behaviour shown in figure 3 , these parameters should be varying. We decided to make $d_{31}$ vary with the electrical field inside a piezo cell, and we laid down:

$$
d_{31}=d_{31 n} \times \frac{E_{\max }}{E_{\max }+\frac{V}{e}}
$$

where $d_{31 n}$ is a value given by the material manufacturer and $E_{\max }$ is a constant parameter depending on the material, not on the plate's size. This modelling is consistent with the experimental data as shown in figure 3 , except for the plate $\mathbf{0}$ for which deflection is under estimated.

Finally, taking into account 4 into 3 yields to writing that $P$ is proportional to $\frac{e^{3} W^{2}\left(E_{\max }+\frac{V}{e}\right)^{2}}{E_{\max }^{2}}$ : the thinner the piezo layer is, the smaller the power losses. This conclusion is consistent with what is found by experimental measurements.

Consequently, increasing the vibration amplitude can be achieved by choosing thin piezoceramics cells: to reach $1 \mu \mathrm{m}$, the device needs lower voltage leading to a smaller amount of power. Then there exists a tradeoff between the level of voltage to reach $1 \mu \mathrm{m}$ and the power consumption leading to an optimized geometry of the tactile plate. By this way, we have shown that it is possible to reduce the power consumption to less than $0.5 \mathrm{~W}$ at the rated vibration amplitude of the plate, while the original tactile plate needed $5 W$. 


\section{Conclusion}

This paper presents a study of power losses in a controlled friction tactile stimulator. We found that optimal design should include power consumption in its cost function. Previous modelling used for the plate's design has been extended in order to take into account the power losses.

Finally, we found that a more convenient design could cut the power losses down by $90 \%$. Consequently, the tactile plate doesn't get warm, allowing the user to play a long time with the device. Moreover, the rated power $(0.5 \mathrm{~W})$ is sufficiently small to allow a power supply from a lightweight power source, or directly from an USB port for example.

\section{Acknowledgement}

This work has been carried within the framework of the INRIA Mint project and is supported by the IRCICA (Institut de Recherche sur les Composants logiciels et matériels pour l'Information et la Communication Avancée)

\section{References}

1. Wagner C.H., Lederman S.J., Howe R.D.: A tactile shape display using servomotors. Proceedings of the $10^{\text {th }}$ symposium on haptic interfaces), 354-355 (2002)

2. Valazquez R., Pissaloux, Hafez M., Szewick J.: Tactile Rendering With ShapeMemory-Alloy Pin-Matrix. IEEE Transactions on Instrumentation and Measurement. vol. 57, $n^{0} 5,1051-1057$ (2008)

3. Summers I.R., Chanter C., Southall A., Brady A.: Results from a Tactile Array on the Fingertip. Proceedings of the EUROHAPTICS 2001, 26-28 Birmingham (2001)

4. V. Levesque, V. Hayward: Experimental Evidence of Lateral Skin Strain During Tactile Exploration. Proceedings of EUROHAPTICS 2003, 261-275, Dublin (2003)

5. Pasquero J., Hayward V.: STReSS: A Practical Tactile Display System with One Millimeter Spatial Resolution and $700 \mathrm{~Hz}$ Refresh Rate. Proceedings of EUROHAPTICS 2003, 94-110, Dublin (2003)

6. M. Biet, F. Giraud, B. Lemaire-Semail: Implementation of tactile feedback by modifying the perceived friction. IEEE TUFFC, vol 43, $n^{0} 1,123-136$ (2008)

7. M. Wiesendanger: Squeeze Film air Bearings Using Piezo-electric Bending Elements. PhD dissertation, EPFL Lausanne - Switzerland (2000)

8. T. Watanabe and S. Fukui: A method for controlling tactile sensation of surface roughness using ultrasonic vibration. Proceedings of IEEE ICRA, vol. 1, 1134-1139 (1995)

9. L. Winfield,J. Glassmire, J.E. Colgate, M. Peshkin: T-PaD: Tactile Pattern Display through Variable Friction Reduction Proceeding of Worldhaptic 2007, 421-426 (2007)

10. M. Biet, G. Casiez, F. Giraud, Betty Semail: Discrimination of Virtual Square Gratings by Dynamic Touch on Friction Based Tactile Displays. Proceeding of the Haptics Symposium'08, 41-48 (2008)

11. Noliac website, URL:http://www.noliac.com/Material_characteristics_-143.aspx 